\title{
Risking and Securing Out of School Children: Parents' Perspective in a Semi-Urban
}

\section{Community}

\author{
Mamonah Ambreen*, Muhammad Athar Hussain**
}

\begin{abstract}
The present research article deals with the perspective of parents regarding the future of their out of school children and their concept of educational development. Qualitative research techniques which includes in-depth interviews, participant observation and FGDs were used for data collection. Bari Imam, near Quaid i Azam University Islamabad was the research site. Purposive sampling technique was used and only those parents were chosen who had out of school children. To understand the parents' perspective about out of school children, the concepts have been borrowed from Social Learning Theory, which has three major components e.g. observation, imitating and then modeling. Results of the study indicated that parents had serious reservations about the educational system of Pakistan and the future outcome of education. They preferred short-term to boost their household economy rather than a long term investment on their children's education which is necessary for the social as well as the personal development. Under the influence of social learning, parents imitating others started sending their children to acquire technical skills, which brought early monetary rewards. Study concluded that, parents were forced to send their children for earning rather than to the schools. Mainstream culture prevailing in the area was to send the children for vocational and technical trainings for rapid monetary benefits. In the current scenario the natives influenced each other which was positive in the context of money and rewards, but negative for the child's educational development.
\end{abstract}

Key Words: Out of school children, educational resources, social impact, family culture.

This Article can be cited as:

Ambreen M., Hussain M A., (2020). Risking and Securing Out of School Children: Parents'

Perspective in a Semi-Urban Community, Journal of Arts and Social Sciences. VII (2), 137-149.

\footnotetext{
*Mamonah Ambreen, PhD Scholar, Allama Iqbal Open University Islamabad.

${ }^{* *}$ Correspondence concerning this article should be addressed to Muhammad Athar Hussain, Assistant Professor, Early Childhood and Elementary Teacher Education Department, Allama Iqbal Open University Islamabad, Muhammad.athar@aiou.edu.pk.
} 


\section{Introduction}

Out of school children has become a great issue all over the world especially in the developing countries where the children's access to education is limited due to a number of factors. In Pakistan, unfortunately the current literacy rate is $59.9 \%$ which is very upsetting (Web-Desk, 2016). The status of education reported by the DAWN highlights the number of out of school children which were 22.84 million in 2016-17 extracted from Pakistan Education Statistics. According to the Minister of Education 51.53 million children aging between 5 to 16 years were still out of school (DAWN, 2019). A number of reasons behind this low enrollment rate but the parent's perception regarding the educational development of their children one of them.

Parents are one of the major influencing factors in educational development of their children. Harris \& Goodall (2007) stated that parents' involvement in the educational out-come is necessary in both ways for the promotion of education in the family or vice versa. In present research study the perception of parents and their understanding towards the educational development and wellbeing of the family has been documented.

A number of studies and surveys have been conducted to identify the impacts of socio-economic factors on the stays of children in School and their attainments in developing and under-develop countries (Jencks, 1972; Campbell, 2009). According to the Breen and Goldthorpe (1997), educational attainments of the parents have the positive influence on the educational development of their children; both mother and father plays different role e.g. fathers' were inspiration for their sons and mothers for their daughters. But in some cases mothers were the prominent and influencing forces to send their children to schools (Fuller et al., 1995; Emerson \& André-Portela, 2007). There were two studies which clearly state that permanent employment of the parents may increase the opportunity for children to stay at schools. Poor families were not inclined towards sending children for education; there is negative relationship of job of parents and the educational development of their children.

There were not only the socio-economic negatively influencing factors; the number of siblings was another important hindrance for education in poor families. Blake (1989) conducted a study in USA in which the number of siblings was negatively co-related to the educational opportunities of the students. The situation also discussed by the Downey (1995) that if parents have more children the resources they have must distributed among them very precisely. Like in Pakistan, poor families have very limited resources, so who will be the one who gets the educational opportunity is the major question amongst the poor. This was not only among the poor families generally, in Botswana, the lower secondary age children have high enrollment rate (1985). The reason could be that all the children participating in economic affairs of household. In developing countries girls have very less opportunities for education, due to less available resources (Parish \& Robert, 1993).

\section{Purpose of the study}

The purpose of the article was to explore the parents' views regarding educational facilities available in the area e.g. type and quality of education and their concerns about the future goals and achievements of their children. The article also identifies the reasons why parents were reluctant regarding the enrollment of their children in schools. On the other hand, the input of children was also included to document their perception about future prospects. It was evident that the investment of human capital is necessary for all social developments. Family development in the age of globalization is not an easy task without education. Present research study deals with the narratives of parents and their standpoint, either work was more important than education.

A number of questions were identified before going into field to find out; 
a. What parents have negative concerns about the educational system of Pakistan?

b. Why they are not sending their children for education?

c. What are their future prospects except education for their children?

Above three leading questions were made to get the information from respondents.

\section{Social Learning Theory}

A number of factors why parents were not sending their children for education were stated earlier. Such behavior developed due to active involvement of social life. Like the social learning theory discussed, behavior develops according to the surroundings (Muro \& Jeffrey, 2008). According to the theory, people learn from their surroundings through different source of interactions with others in a particular social context. The theory worked in three phases i.e. a) observation, b) imitating and c) modeling. In a social context people develop similar behavior when they share same economic status, same profession, same residential area and same social stratification (Bandura, 1971, 1977). This theory bridges the behaviorist learning and cognitive learning theories (Muro \& Jeffrey, 2008). New behaviours can be acquired by observing and imitating others (Bandura, 1963). However, the learning cannot take place without observation. The observation of a particular personality trait, its rewards and motivation through that rewards for changing the personality of others cannot be done separately. This process cannot be bound by age, time or space. When a particular behaviour is rewarded regularly, it will most likely continue; on the contrary, if a particular behaviour is constantly punished, it will most likely end (Bandura, 1963). In health behaviours the social learning theory influenced a range of traits e.g. hoteling, smoking, late night sleeps and dietary patterns (Leatherdale et al., 2005).

The principals of social learning theory as stated earlier were assumed to operate in the same way throughout life of individuals. New learning can occur at any stage of life through modeling (Newman \& Newman, 2007). The persons who are being observed are called models and the process is modeling. Bandura (1963) stated that the second and third stage of learning can occur when individuals value the positive traits of others on the basis of their personal cognitive development. The process also includes the moral judgments of positive and negative which can be developed through modeling.

\section{Research Methodology}

This particular research was conducted in qualitative paradigm and ethnographic model was used for data collection. Participant observation, key informants, in-depth interview guide were administered to get the view point of parents regarding educational developments, attainments and their perception towards enrollment of their children. In-depth interviews were conducted from two types of families, those who readmitted their children for education and from those who do not send their children for education. Purposively, eight families four from first and four from second type of families were selected on convenient bases from Bari Imam Locality. The area was also under the review of PhD study so; selection of households for the research article was easy. The area has semi-urban characteristics abundance of educational institutes, and OOSC made the area more suitable for study. It was evident that due to lack of educational institutes people forced to send their children for earning purposes, but in the current case, the situation is different. Numbers of educational institutes were present there but parents were reluctant to enroll their children. The focus of the interviews was to find out parents' perception regarding the investment of children for the wellbeing of families.

LeCompte and Preissle (1993) gives six type of interviews but in present research in-depth interviews were conducted from parents (father and mother) for extensive information, overall, ten (five mother and five fathers) and three children ranging 12, 15 and 16 years old were interviewed. The semistructured interview guide was prepared before conducting interviews and was administered with a number of questions (guideline). Conceptualization of research questions provided thematic dimensions which give 
directions for accurate information and helped in both ways e.g. making the researcher more fixed towards objectives; and looked into causes and consequences. Thematic analysis was done after collection of interviews. Data were divided into four major themes e.g. perception of parents, future rewards, available educational facilities and the interest of children which are further elaborated.

\section{Results and Discussion}

Cultural norms and the socialization process are influenced and shaped by the values, cultural beliefs of the community (Alavi \& McCormick, 2004). In this regard, family culture will influence the choices and behavior of children towards education (Wang \& Degol, 2013; Goyette, 2008). The type of character which the children have is developed by the families, parents and the shared family values (Gibbons, 2009; Fucci \& Cavaletto, 2012) which motivate them towards educational achievements (Fletcher et al, 2010). Family environment provides aspiration and influence children's future planning (Wang \& Degol, 2013). The selection of formal or informal education by the children and the parents depends on family culture as well as appropriateness regarding economic status (Walker \& Clark, 2010). In this context, the practice of cultural values seem as collectivism, in South Asian countries like Pakistan, the values and the preference practiced collectively rather than the individually which was practiced in West or other developing countries (Alavi \& McCormick, 2004; Wang \& Degol, 2013; Siah et al., 2014). It was also documented that collectivism is not only the decision among the families regarding the formal or informal educational sector (Sánchez-Medina et al, 2014).

Along with some other factors, economic resources are the major factor of high rate of out of school children. Lohani et al (2010) directly linked the parents' occupational significance in selection of school enrollments and educational expenditures. Dynamics of the household also direct the schooling decisions. Stated by the work of Acar et al (2016) parents' good jobs motivated for investment on the children education.

Family size is another important aspect in which families have so much expenses so the academic expenditure considered the external expense. According to Symeou et al. (2014) stated that the students who are at the risk of drop out majorly belongs to the less educated families. Another study stated that the characteristics of the friends also related to the risk of their dropping out (Staff \& Kreager, 2008). The study of Steinberg (1996) suggested that impact of peers on dropouts must be included when assessing the causes of dropouts because peer's influence most of the time outweigh the customs of families towards shaping various adolescent behaviours. Parent's perception towards the girls' education is another important aspect which create hinder and promote less enrollment of girls in schools (Aslam \& Kingdon, 2008; Lohani et al., 2010). Observance of Pardah, security and safety of female in schools, mobility issues are some of the other underlying reason for less enrollment of girls at school level.

\section{Parental Preferences}

Parents took the decisions according to the available resources but on the other hand children were under the influence of peer groups. It was documented that the sense of competition (negative competition) also existed among the youth. They were inspired by the material things of others, and forced their parents to purchase those items for them i.e. bikes, smart phones etc. The culture of parade is common, show off the wealth is common through dresses and gadgets.

In such scenario, parents were under pressure. Children wanted to get all the instruments and facilities their friends have, that is why a gap between children and their parents existed. Parents wanted to send their children for education, but due to lack of economic resources and output of children in education, parents were forced to send them for technical education. A father stated, 'I want to educate my children, but they were inspired by the others rather than considering their own economic worth. They were in the 
competition of Maliks and Syeds in the area. We belong to a simple family with less economic resources, but for the happiness of my children I got a loan and purchased a motor bike for them. Now they are asking for smart phone which I cannot afford. I am worried, if I would not fulfill their desire they may get involved in bad activities or harm themselves to tease me.'

Education is not the only option for development of children in the community. Parents had a better exposure due to a continuous interaction with the people who come across Pakistan to visit Bari Imam Shrine. A father stated, 'I am running a hotel in the Bari Imam from last 2 decades. Initially it was run by my father, now I am running it and after me the responsibility would be on the shoulders of my son. If we talk about the education, yes it is good but just for better understanding. I know a lot of educated boys bearing a good moral character in the area but they do not have money to bribe or political recommendation to find a job that's why they are doing patty work for their survival. In the past educated people were respected in the society. There were more job opportunities, everybody was getting a job after competing education. Now every street has three to four schools. The easy access to education or the excessive availability of educational institutes made it worthless. My elder son completed his matriculation, he wanted to get admission in college for his FSc but I refused as there is no job security after completing the education. I asked him to join our family business. He is doing well and has a better understanding because of his education'

\section{Future Rewards}

The natives perceived education in the light of future rewards and its long term benefits. Children and their parents estimated its worth according to the future employment which could facilitate them in near future and bring prosperity. The people with low literacy levels like in rural areas where agriculture is the major source of livelihood do not give importance to the formal education. They prefer technical education for their children and their children are also less interested in completing their formal education, there is hardly anyone who could reach up to the university level (Tansel, 2002; Colclough, Rose \& Tembon, 2000). In urban areas the formal sector needs formal qualified individuals, so parents are more interested to send their children for formal education. The gender sensitivity may not appear because children are weighted by their end productive lives (Colclough, Rose \& Tembon, 2000; Song, Simon \& Knight, 2006). Everyone has the opportunity to send their children for formal education.

Long term benefits of education for their children is not only the consideration for the parents, they think in terms of how their children will facilitate them in their old age. In South Asian cultures male members of the household considered to look after the parents in later age, that is why parents are more inclined towards sending their boys to schools and are investing more on them. On the other hand girls are supposed to leave the parents after their marriages and live with their husbands, so residential rule is a barrier to female education. The parents prefer boys over the girls for educational investment as they are the permanent members of the family (Colclough, Rose \& Tembon, 2000). Rankin and Aytac (2006) stated that the girls from patriarchal family's remains at home and those who belong to the families with less male dominance has a better chance to get education. Such problem is not similar all over the world. In Indonesia, parents spend on their girls' education even after their marriages where virilocal residential rule is observed. The girls leave the parents and establish a new residence with her husband (Levine \& Kevane, 2003). Eloundou-Enyegye \& Calvès (2006) explored the patrilocal residential structure in Sub-Saharan Africa, where most of the girls migrate to the nearby countries after their marriages. They keep on sending money back to their parents. In such societies educated girls are sending more remittances to their parents in return to the investments made by their parents on education when they were unmarried and living with their parents.

The natives had very higher expectations from their children's education. They expect high level jobs for their children after the completion of their education. Dreams of the parents were higher than efforts 
they put in for their children. As discussed earlier, parents' education was the major source of inspiration towards children's education. They could understand the hardships and outcomes of education, on the other hand the illiterate parents could not understand the importance of education.

'Why should we send our children to schools?' was the most frequently asked question by the parents during interviews. The prospects and the benefit of education were always translated into the monetary terms. A father stated, 'If I spend thousands on my child's education, what benefits would I have? Let me tell you, nothing in return. You can see the literature, newspapers or you can see around yourself a lots of unemployed boys and girls, who have higher education from good universities. I know a neighbor of mine who has an MPhil degree from QAU, but from last three years he does not have a job and teaching in Mashal School on Rs.5000 per month. This is the only return of education system in Pakistan. Then why should I spend so much on a waste, rather than sending my child for some technical skill like motormechanic etc. which will be helpful to earn a better life.'

In the natives' opinion the ultimate outcome of the education was the prosperous life of the family but without considering its hardships. It was documented that the illiterate or the less educated parents were reluctant to send their children to schools because in their opinion, 'sending children for education is just a waste of time money and age of their children.' Another respondent (father) stated that, 'Sending my children to school is not difficult for me like many other middle class parents, but the outcome of education remains unsatisfactory due to lack of job opportunities and the culture of approbation in all sectors of life.'

The parents either educated or un-educated had reservations on the educational outcomes. A father stated, 'Abundance of education is the major reason of lack of job opportunities. The government must act smartly and banned all the institutions which are opened for investment purposes only.' In the community people are of the view that education is the way of earning. They think that if you own a house in the area and have good communication skills, you can establish a school from where you can earn enough for your livelihood.

Negligence of government policies is not a new phenomenon. The natives have very different views regarding the political particles and the establishment. A respondent (father) stated, 'every political party is providing benefits to its own workers e.g. PPP, PML (N), PML (Q) PTI etc. There is no proper recruitment mechanism. Whenever any of these political parties comes in power they appoint their political workers in educational sector without any proper scrutiny, test or interview. Though number of jobs are given to deserving candidates, but majority of the seats are distributed among the politicians that is why every institution of the country has bundle of approbation recruiters.'

Such type of officers and staff are burden on the government and on the other hand it is injustice with deserving and competent candidates who do not have any approbation of political leaders or the establishment. In such situations people have very serious reservations that CSS, PMS, FPSC are the only institutions for children, but the supply of educated candidates and demands in placement offices always remained imbalance.

\section{Educational Facilities}

Access to schools or provision of education is not the only factors behind keeping the children out of school. According to some studies Colclough, Rose and Tembon (2000) quality of the education provided by the schools matters (Handa, 2002; Ersado, 2005). If we analyzed the provision of facilities in schools, the climate of schools could be categorically distributed into three spheres e.g. school management, process of education which includes the quality of education and the school structure and curriculum of schools (Brault, Janosz \& Archambault, 2014). The climate of the schools for children plays a significant role for selection of schools (Brault, Janosz \& Archambault, 2014; Pecháčková, Navrátilová, \& Slavíková, 2014). 
In different cases the perception as well as expectation of parents and children remains high for achievement of future goals (Atkins et al., 2015).

The education provided in the schools is very important. This has an association with the future benefits for student and their families. In different areas of the world for example in China (Pecháčková, Navrátilová, \& Slavíková, 2014; Atkins et al., 2015) and Bolivia (Punch, 2004) bad school services have negative impact on the children and their long stay in schools e.g. the push-out effects. Bergmann (1996) co-related the job opportunities and dropout as well as quality of education provided in schools which is negative in rural areas.

Various studies showed that parents have reservations on the low quality of education. Their children may get less knowledge through such services and perform less in future (Colclough, Rose \& Tembon, 2000; Buchmann \& Hannum, 2001). Fuller et al., (1995) study shows, if mothers are satisfied with the quality of education their girls may dropout at a lesser rate and could complete their education. Like in previous researchers stated in the study, presence of female teachers is other major issue. Culturally and morally this is against the values of Pakistani society that girls are being taught by male teachers at primary and secondary level (Colclough, Rose \& Tembon, 2000; Dee, 2005; Leach, 2006). Some other factors, worrying the parents, identified by the scholars are unavailability and inaccessibility of community to schools, unsatisfactory conditions prevailing in the schools for the children. Teacher-student relationship is so important to keep the children at school. Teacher-student relationship majorly characterized by the affection and the problem solving tactics during academic life e.g. lessons, work-plan, homework and interactive classes. The relation may further observe admiration, love and respect among the students and towards teacher and vice versa. If this relationship deteriorates at any stage it also ads up school dropout (Uller, Judith \& Keiley, 1995).

The second major issue in the research locale was the lack of good educational institutes. The schools were providing poor services. School buildings and the other facilities provided by the schools were also very poor which forced parents to not enroll their children in schools. It was also documented that parents were reluctant to send their girls for higher education. According to them, up to primary or secondary level education was sufficient for girls because they only had to take care of their in-laws after marriage so there was no need to educate them up to higher level. Due to the observance of Purdah and insecurity of female hood parents were more concerned about the outdoor activities of their girls. A mother shared, 'My daughter was enrolled in Mashal Public School. After the completion of her intermediate, my mother in law advised me to discontinue her education. She became very angry upon this of my decision. Later I talked to her in detail and took her in confidence. After a while she became normal quit the resistance. The area is full off bad people, in Noor Pur the situation is same like in Muslim Colony, boys wandering in streets which could be risky for teenage and adult girls.'

Among the natives educating the children was considered as the way of development in all aspects e.g. human, cognitive, personality and every aspect of life. Community members were inspired from educated individuals living around them. But now a day the effectiveness of education-personality development model vanished. Educated and uneducated boys act like the same; both were engaged in evil activities and were not under the influence of parents. A respondent (mother) stated, 'In our time, getting education was a noble profession; people respected the educated individuals because they have positive and good personality traits and participated in the well-being of the community. But now the situation is worse, May Almighty Shower His Blessing upon us. The dance culture in educational institutes, boys' and girls' co-education and use of mobile phone made the scenario even worse. I asked my son all the time to not send his children to schools because schools produce nothing but destroying the culture and the Muslim personality of children.' 
Here in Pakistan, education is long term investment and needs patience and commitment. Most of the community members were living hand to mouth. They only had their children as an earning opportunity and to survive in ease. In such situations, when asked about the government facilities e.g. free education, free uniform and books, a respondent (mother) stated, 'What can we do with such free education, after completing the education will he get a good job in the government office or even in any private office. After investing ten to fifteen years on our children we are getting nothing in return, just a school teacher or extra coaching tutor is not what we are dreaming for. In my opinion all the schools should be closed and technical schools may be opened from where our children could get technical training and start earning early. This is the only way our survival becomes easier, which is most important need of time.

\section{Student Interest}

From last two decades, numbers of scholars were engaged to find out the effectiveness of choices towards the educational development of children (Leung et al, 2014). Children's interest in any field influences their future goals and the inclination towards the desired goals (Chung, 2013). Due to inflation and less job opportunities the choice and liking for educational development is very low (Vaughn \& Witko, 2013) children were motivated towards skill enhancement and vocational education which will return back the efforts in short time. According to the Leung et al., (2014) children's interest towards their future goals has very strong relationships (Mendolia \& Walker, 2014; Yang \& Chang, 2009). The study of Lent et al., (2010) and Leung, et al., (2014) under the influence of Holland RIASEC Model, stated that with the help of social support e.g. from parents or from their own experiences has a very strong relationship regarding their future field of choice. The same findings were also documented by the Mendolia and Walker (2014) with the help of matching method. Lent et al., (2008) get data from 209 Universities in USA and stated that competency, self-capability and output expectations were more important than individual interest in the selection of education or any other career.

In the locale parents' effort towards the educational development of their children remained ineffective until the prospects of children were similar to the parents. In the community it was observed that children had a number of other commitments and engagements which directly influenced their educational life. In the community a number of evil activities were practiced e.g. children between the ages of 8 to 15 years were engaged in smoking and other kind of drugs. It was due to negligence of parents. When asked to the respondents about this situation a mother stated, 'Children are out of our control, if we punish them on their evil acts they start thinking as if we are their enemy and may leave the house, that is why we mothers hide such type of issues from their fathers.'

Natives narrated a story of two brothers who were taking drugs and died because of high dose. When their mother came to know about their addition she restricted their movement and confined them within the house. She used to lock them in a room whenever she had to go out for work. Once in her absence their friends entered in their room and smoked together. Younger brother died first and the elder died after one month. Mother of the children left the area and went to her brother's home in Kashmir. Another respondent stated that her son was addicted to smoking, she was working as maid in different houses, she left the community and sends her son to her brother's home (he was police man and very strict towards childe socialization) after the continuous care of four months her son quit smoking and engaged in education.

When asked to the children what type of life they want in future a 17-year-old boy stated, 'My father worked hard all the day for feeding us, it is not possible for me to remained in school under the fan in shelter, so I quit the education in $7^{\text {th }}$ grade and now working with him to make our family happy and prosperous.' When asked him about the education of his other siblings he narrated, 'my two brothers and one sister studying in government school but their performance is not satisfactory. They may or may not pass their exams. My father asked many times to quit their education but I resisted for them.' 
Due to lack of economic resources, those boys who were above the age of 15 years, they eagerly participated in economic affairs of the family. Those who were not attached with any of their parents remains under the influence of bad company. A boy stated that, my father is not loving me, he remains busy all the time at hotel when I visited there he neglected my presence and remains busy in his work, he is my father but I cannot feel anything for him.'

Such type of feeling when shared with mothers' they blamed the poverty as the central point of such issues. Due to less resources fathers all the time remains busy for the betterment of their families and in this situation they neglect their children and family. On the other hand when asked fathers about such issue one of my respondents (father) stated, "we spend all the day outside in harsh environment for the ease of our families and children.'

\section{Conclusion and Recommendations}

The study concluded that, the understanding of parents towards lesser enrollment of children (never admitted to the schools and dropout) developed through the adaptation of popular culture of the area. The parents gave less importance to the children education due to the number of external factors. Parents took the decisions according to the available resources but on the other hand children were under the influence of peer groups. The culture of parade is common, showing off the wealth is common through dresses and gadgets that is why earning engagements had more importance in the community. In such scenario, parents remained under pressure for the purchase of such gadgets. Educational investment on the children was wasted due to school's environment e.g. no motivation in schools, no future rewards and the less intentions of children towards educational development over earning engagements. The natives estimated the worth of education according to the future employment which could facilitate them in near future and bring prosperity and how their children will facilitate them in their old age. It was observed that the ultimate outcome of the education explained through the prosperous life of the family without considering its hardships. The parents either educated or un-educated had reservations on the educational outcomes that is why engagement of children for technical skills were prominent strategy. Another major issue was the provision of quality education, schools were in abundance but providing poor services along with poor structural conditions which forced parents to not enroll their children in schools. Due to the observance of Purdah and insecurity of female, parents were more concerned about the education of their girls. It was observed that children had a number of other commitments and engagements which directly influenced their educational life. Lack of economic resources, boys who were above the age of 15 years, eagerly participated in economic affairs of the family. Natives blamed 'poverty' as the central point of such issues.

Keeping in mind the Social Learning theory, it was observed that the natives were under a great influence of some demographic and economic variables, that's why the behavior of the community towards education remained negative. Individuals learned from their surroundings and tried to be the part of mainstream culture. In the current scenario, all the community members were less educated especially the women, shared same geo-physical background, majority of them was settlers, engaged in odd jobs like daily wages etc. The children also learned from the surroundings/environment which made them more open to the reality of being the part of that particular group. Personal understanding, parents' point of view, friends, peer, economic class, and social-gathering, are some of the factors which showed that the surrounding environment had a major influence on the children because due to less education the primary groups had a less potential to influence and to dilute the negative impacts of the society on children's personalities. The study further highlighted some issues which acted as barriers to the children's education and school attendance including Purdah, large family sizes with greater number of children and less economic resources for their education. 
The general characteristics of the community indicated that the limited economic resources, low self-esteem of parents, poor quality of education and the future worries of parents were some of the major issues which forced the parents to send their children to work, which would be helpful for family's economic resources and for the future of children as well. Learning a skill to earn livelihood is more attractive than spending ten to fifteen years in memorizing alphabets, math equations and stories. The natives' perception about the long term and short term benefits in the context of education and vocational/skilled based education for the economic development of families were one of the main reason of out of school children in Bari Imam Area.

\section{References}

Acar, O., E., Gulnap, B., \&Cilasum, M., S. (2016). An empirical analysis of household education expenditure in Turkey. International Journal of Educational Development, 51, 23-35.

Alavi, B. S., \& McCormick, J. (2004). A cross- cultural analysis of the effectiveness of the Learning Organization model in school contexts. International Journal of Educational Management, 18(7), 408-416.

Aslam, M. \& Kingdon, S., G. (2008). Gender and household education expenditure in Pakistan. Applied Economics, 40 (20), 2573-2591.

Atkins, M. R., Johnson, D. M., Force, E. C., \& Petrie, T. A. (2015). Peers, parents, and coaches, oh my! The relation of the motivational climate to boys' intention to continue in sport. Psychology of Sport and Exercise, 16, 170-180.

Bandura, A. (1963). Social learning and personality development. New York: Holt, Rinehart, and Winston.

Bandura, A. (1971). Social Learning Theory: General Learning Corporation. New York: Holt, Rinehart, and Winston.

Bandura, A. (1977). Self-efficacy: toward a unifying theory of behavioral change. Psychological review, 84(2), 191.

Bergmann, H. (1996). Quality of Education and the Demand for Education. International Review of Education, 42, 581-604

Blake, J. (1989). Family size and achievement. Berkeley: University of California Press.

Brault, M.-C., Janosz, M., \& Archambault, I. (2014). Effects of school composition and school climate on teacher expectations of students: A multilevel analysis. Teaching and Teacher Education, 44, 148159.

Breen, R., \& Goldthorpe, J H. (1997). Explaining Educational Differentials: Towards a Formal Rational Action Theory. Rationality and Society, 9, 275-305.

Buchmann, C. \& Hannum, E. (2001). Education and Stratification in Developing Countries. Annual Review of Sociology, 27, 77-102.

Campbell, M. E. (2009). Multiracial Groups and Educational Inequality: A Rainbow or a Divide? Social Problems, 56(3), 425-446.

Chernichovski, D. (1985). Socio-economic and demographic aspects of school enrollment and attendance in rural Botswana. Economic Development and Cultural Change, 33, 319-32

Chung, Y.-C., Lin, C.-Y., Huang, C.-N., \& Yang, J.-H. (2013). Perceptions on gender awareness and considerations in career choices of medical students in a medical school in Taiwan. The Kaohsiung Journal of Medical Sciences, 29(11), 629-35. 
Colclough, C., Rose, P. \& Tembon, M (2000). Gender inequalities in primary schooling. International Journal of Educational Development, 20, 5-27.

Dawn. $22.84 m$ children in Pakistan still out of school, says official report. Islamabad, April 19, 2019.

Dee, T. S. (2005). A Teacher Like Me: Does Race, Ethnicity, or Gender Matter? The American Economic Review, 95, 158-165.

Downey, D. B. (1995). When Bigger is not Better: Parental Resources and Children's Educational Performance. American Sociological Review, 60, 746-761.

Eloundou-Enyegye, Parfait M., \& Emmanuèle Calvès, A (2006). Till Marriage Do Us Part: Education and Remittances from Married Women in Africa. Comparative Education Review, 50, 1-20.

Emerson, P. M., \& André-Portela S. (2007). Child Labor, School Attendance, and Intra-Household Gender Bias in Brazil. The World Bank Economic Review, 21, 301-316.

Ersado, L. (2005). Child Labor and schooling decisions in urban and rural areas: comparative evidence from Nepal, Peru, and Zimbabwe. World Development, 33 (3), 455-480.

Fletcher, J., Greenwood, J., \& Parkhill, F. (2010). Are schools meeting their clients' expectations? Parents voice their perceptions about children learning to read in schools today. Teaching and Teacher Education, 26(3), 438-446.

Fucci, S., \& Cavaletto, G. M. (2012). Educational Choices of the Elites. Autonomy and Responsibility of Italian and Foreign Children between Family and School. Procedia-Social and Behavioral Sciences, 46, 4990-4994.

Fuller, B., Judith D. Singer \& Keiley, M (1995). Why Do Daughters Leave School in Southern Africa? Social Forces, 74, 657-680.

Gibbons, S. (2009). Choice and Participation in Higher Education Anna Vignoles, (January). CEE DP 101 Access,

Goyette, K. A. (2008). College for some to college for all: Social background, occupational expectations, and educational expectations over time. Social Science Research, 37(2), 461-484.

Handa, S. (2002). Raising primary school enrolment in developing countries. Journal of Development Economics, 69, 103-128.

Harris, A., \& Goodall, J. (2007). Engaging parents in raising achievement: Do parents know they matter? Research Report DCSF-RW004: Department for Children, Schools and Families.

Jencks, C. (1972). Inequality: A Reassessment of the Effect of Family and Schooling in America. New York: Basic Books.

Leach, F. (2006). Researching Gender Violence in Schools. World Development, 34, 1129-1147.

Leatherdale S. T., Cameron R., Brown K. S. \& McDonald P.W. (2005). Senior smoking at school, student characteristics, and smoking onset among junior students: A multilevel analysis. Preventive Medicine, 40, 853-859.

LeCompte, M. \& Preissle, J. (1993). Ethnography and Qualitative Design in Educational Research (second edition). London: Academic Press.

Lent, R. W., Paixão, M. P., Silva, J. T. Da, \& Leitão, L. M. (2010). Predicting Occupational Interests and Choice Aspirations in Portuguese High School Students: A Test of Social Cognitive Career Theory. Journal of Vocational Behavior, 76(2), 244-251. 
Lent, R. W., Sheu, H.-B., Singley, D., Schmidt, J. a., Schmidt, L. C., \& Gloster, C. S. (2008). Longitudinal relations of self-efficacy to outcome expectations, interests, and major choice goals in engineering students. Journal of Vocational Behavior, 73(2), 328-335.

Leung, S. A., Zhou, S., Ho, E. Y.-F., Li, X., Ho, K. P., \& Tracey, T. J. G. (2014). The use of interest and competence scores to predict educational choices of Chinese high school students. Journal of Vocational Behavior, 84(3), 385-394. doi:10.1016/j.jvb.2014.02.010

Levine, D. \& Kevane, M. (2003). Are Investments in Daughters Lower when Daughters Move Away? Evidence from Indonesia. World Development, 31, 1065-1084.

Lohani, S, Singh, R., B., \&Lohani, J. (2010). Universal primary education in Nepal: Fulfilling the right to education. Prospects, 40, 355-374.

Mendolia, S., \& Walker, I. (2014). The Effect of Personality Traits on Subject Choice and Performance in High School: Evidence from an English Cohort. Economics of Education Review, 43, 47-65.

Muro, M., \& Jeffrey, P. (2008). A critical review of the theory and application of social learning in participatory natural resource management processes. Journal of environmental planning and management, 51(3), 325-344.

Newman, B. M., \& Newman, P. R. (2007). Theories of human development: Lawrence, Erlbaum.

Parish, W. L., \& Robert J. W. (1993). Daughters, Education, and Family Budgets; Taiwan Experiences. The Journal of Human Resources, 28, 863-898.

Pecháčková, Y., Navrátilová, Z., \& Slavíková, P. (2014). Social Climate in the Environment of Primary Schools. Procedia-Social and Behavioral Sciences, 112 (ICEEPSY 2013), 719-724.

Punch, S. (2004). The impact of primary education on school-to-work transitions for young people in rural Bolivia. Youth \& Society, 36, 163-182.

Rankin, B. H., \& Aytaç, I. A. (2006). Gender Inequality in Schooling: The Case of Turkey. Sociology of Education, 79, 25-43.

Sánchez-Medina, J. A., Macías-Gómez-Stern, B., \& Martínez-Lozano, V. (2014). The value positions of school staff and parents in immigrant families and their implications for children's transitions between home and school in multicultural schools in Andalusia. Learning, Culture and Social Interaction, 3(3), 217-223.

Siah, P. C., Ong, S. B. C., Tan, S. M., \& Sim, C. P. (2014). Perception on Chinese values: A comparison of Chinese secondary students studying at national secondary schools and Chinese independent schools in Malaysia. The Social Science Journal.

Song, L., Simon A. \& Knight, J (2006). Why Do Girls in Rural China Have Lower School Enrollment? World Development, 34, 1639-1653.

Staff \& Kreager (2008). Too cool for school? Violence, peer status and high school dropout. Research Gate. DOI: 10.1353/sof.0.0068

Steinberg, L. (1996). "Beyond the classrooms: Why school reforms has failed and what parents need to know." A Touchstone Book: Simon and Schuster Publishers.

Symeou, L., Raquel-Amaya Martínez-González \& Alvarez-Blanco, L., (2014). Dropping out of high school in Cyprus: do parents and the family matter?, International Journal of Adolescence and Youth, 19:1, 113-131, DOI: 10.1080/02673843.2012.717899.

Tansel, A. (2002). Determinants of school attainment of boys and girls in Turkey. Economics of Education Review, 21: 455-470. 
Uller, B., Judith D. S. \& Keiley, M. (1995). Why Do Daughters Leave School in Southern Africa? Social Forces, 74, 657-680.

Vaughn, M. G., \& Witko, C. (2013). Does the amount of school choice matter for student engagement? The Social Science Journal, 50(1), 23-33.

Walker, M., \& Clark, G. (2010). Parental choice and the rural primary school: Lifestyle, locality and loyalty. Journal of Rural Studies, 26(3), 241-249.

Wang, M. T., \& Degol, J. (2013). Motivational Pathways to STEM Career Choices: Using ExpectancyValue Perspective to Understand Individual and Gender Differences in STEM Fields. Developmental Review, 33(4), 304-340.

Web-Desk (2016). Pakistan's literacy rate rise to 59.9 percnet: Baligh Ur Rehman. The News Tribe, retrieved 18-04-2019 from https://www.thenewstribe.com/2016/01/01/pakistans-literacy-raterises-to-59-9-percent-baligh-ur-rehman/

Yang, F.-Y., \& Chang, C.-C. (2009). Examining High school Students' Preferences toward Learning Environments, Personal Beliefs and Concept Learning in Web-based Contexts. Computers \& Education, 52(4), 848-857. 